\title{
Fatigue performance and life prediction of CFRP plate in the RC bridge roof reinforcement
}

\author{
Xin Yuan ${ }^{\mathrm{a} *}$ (D), Wei Zheng ${ }^{\mathrm{b}}$ (D) Chaoyu Zhu $^{\mathrm{a}}$ (D), Baijian Tang ${ }^{\mathrm{a}}$ (D) \\ a School of Civil Engineering, Suzhou University of Science and Technology, Suzhou, 215011, P. R. China. Email: yuanxin@mail.usts.edu.cn, \\ zhuchaoyu@126.com, tangbaijian@163.com \\ b Suzhou Zhong-Heng Access Bridge Co., Ltd. Suzhou, 215000, P. R. China. Email: robinwll@163.com \\ * Corresponding author
}

http://dx.doi.org/10.1590/1679-78255789

\begin{abstract}
This paper investigated the fatigue properties and theoretical research on Carbon-Fiber-Reinforced Polymer (CFRP) RC bridge roof with new deck-pavement material. Two deck pavement schemes of CFRP-reinforced specimens were designed and tested. Four-point flexural fatigue tests were carried out on the specimens. The fatigue crack propagation, the deflection development and the CFRP strain under bridge fatigue load were researched. The test results show that the CFRP plate-reinforced specimens crack resistance performance can be improved and can bear the fatigue test load of two million times. Combined with the characteristics of the crack growth rate and fatigue damage accumulation of CFRP plate-reinforced bridge roof specimens, the fatigue life prediction analytical model for CFRP plate reinforced RC bridge roof was obtained. The fatigue life prediction model agrees well with the experimental results. The model proposed in this paper could be applied to predict the fatigue life of the CFRP plate-reinforced RC bridge roofs.
\end{abstract}

\section{Keywords}

CFRP plate; concrete; bridge reinforcement, damage accumulation, fatigue life; predictive analysis

\section{Graphical Abstract}
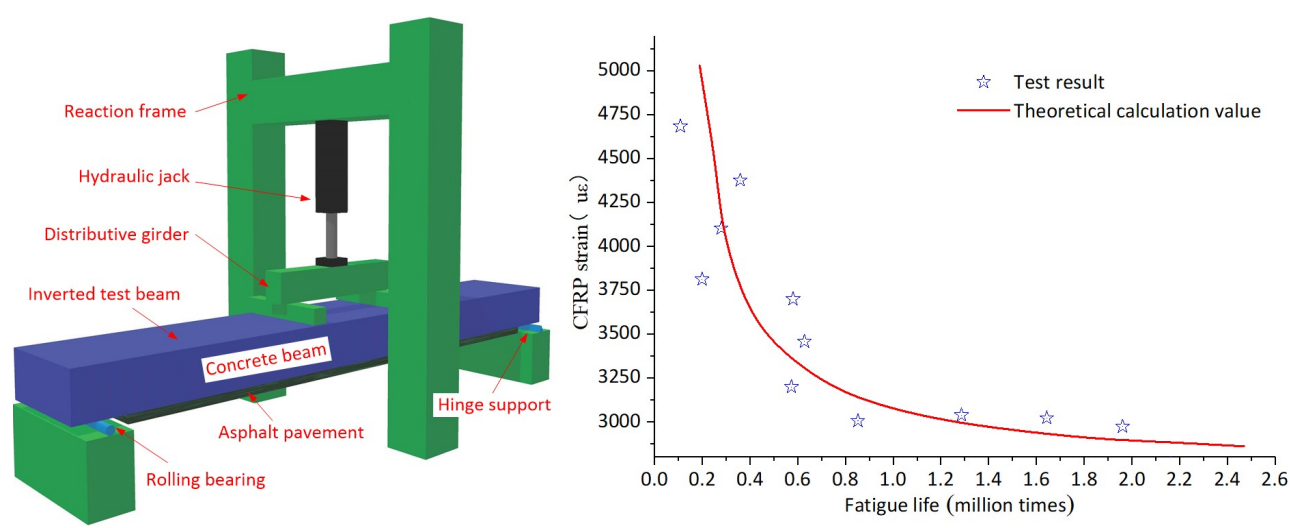

Received: September 09, 2019. In Revised Form: January 12, 2020. Accepted: January 23, 2020. Available online: January $27,2020$. https://doi.org/10.1590/1679-78255789

(c) (i) Latin American Journal of Solids and Structures. ISSN 1679-7825. Copyright (C) 2020. This is an Open Access article distributed under the terms of the Creative Commons Attribution License, which permits unrestricted use, distribution, and reproduction in any medium, provided the original work is properly cited. 


\section{Introduction}

Carbon Fiber-Reinforced Polymer (CFRP) with great material performance has been widely applied in various aspects after its invention, and its mechanical properties have also been extensively studied (Kalavagunta et al., 2014; Barile et al., 2019; Zhang et al., 2019; Yang et al., 2019; Yuan et al., 2019; Saleem et al., 2019). As an effective alternative to traditional materials for strengthening and repairing damaged structures, CFRP-reinforced bridge structure has been extensively investigated (Lu et al., 2018; Peng et al., 2014; Hosseini et al., 2019; Shukri et al., 2018; Mashrei et al., 2019). Zhuang et al. (2018) conducted an experimental study on the CFRP reinforced seriously damaged concrete beam. Different parameters were investigated and it demonstrated that CFRP plate can have good contributions to the performance of the damaged concrete beams. Siddika et al. (2019) researched the techniques and applications of the CFRP reinforced concrete beam, and concluded that CFRP can be applied in the strengthening the damaged concrete beams. In addition, the performance of the CFRP reinforced steel beam is also studied by several researchers. Zeng et al. (2018) investigated the interface performance and the failure modes of the CFRP reinforced steel beam by experiment and simulation method. The proposed finite element mode has been experimentally demonstrated that can be applied in predicting the flexural behavior of CFRP reinforced steel beam. Li et al. (2019) studied the fatigue repair of cracked steel plates with different kinds of CFRP and adhesive. The failure mode and fatigue life were used to evaluate the fatigue performance of the CFRP reinforced steel beam.

Due to the repeated load, the bridge structure often leads to structural failure due to material fatigue. The fatigue life of the material is related to the magnitude of the repeated load value. The lower fatigue life of the structure is usually associated with a higher load value. As the bridge is subjected to increasing fatigue loads during service, it is necessary to extend the service life by reinforcement. For the bridges strengthened with CFRP plates, different experimental and theoretical analysis have been carried out on the fatigue performance and fatigue life of the CFRP reinforced structures. The fatigue performance of CFRP-reinforced bridge deck slabs was investigated by Ju et al. (2017). The fatigue capacity was obtained by using the equivalent number of cycles and indirect fatigue evaluation. It was found that the ultimate fatigue loading should be analyzed based on the variable amplitude loading cases. Song and Hou (2017) proposed a fatigue assessment model for CFRP reinforced concrete beam by considering the fatigue properties of materials. It concluded that fatigue behavior of CFRP reinforced beam can be controlled the fatigue development of steel bar through parametric analysis. Guo et al. $(2018,2019)$ studied the fatigue crack propagation performance of the CFRP reinforced concrete beam. Fatigue crack propagation experiments were also conducted by using the digital image method, and a modified calculation model was also proposed based on the experimental and simulation results.

However, bridges are often subjected to various types of environmental actions while being subjected to vehicle loads. In the case of the coupling effect of the vehicle load and the harsh environment effect, it is more difficult to study the fatigue behavior of the bridge structure. Several studies have been carried on the fatigue performance of CFRP plate reinforced structure under different harsh environment. Li et al. (2017) studied the fatigue performance of the CFRP-reinforced RC beams under high temperature and high humidity, and the fatigue crack propagation behavior was also analyzed through experiments and numerical study. Liang et al. (2018) studied the fatigue bonding behavior of CFRP-concrete interface after wet-dry cycle action. A reliability index was analyzed by considering the coupling effect of wet-dry action and load. Lin et al. (2019) investigated the fatigue behavior of CFRP reinforced concrete bridge under the effect of both high temperature and vehicle loads. A fatigue testing method was proposed and the fatigue damage mechanism was analyzed as well. The existing research mainly focuses on the fatigue performance of CFRP-reinforced 
structures in conventional and special environments, and the research on the fatigue life and the life prediction under harsh environments is relatively rare.

This paper investigates the fatigue properties and theoretical of CFRP plate-reinforced bridge roof. The CFRP plate-reinforced bridge roof specimens were designed and constructed. Four-point flexural fatigue test were carried out on the specimens. The fatigue failure and debonding damage was observed and discussed. Compared with the static load specimens, the crack development morphology and law of the specimens under fatigue cyclic loading were given. Under fatigue loading, even if the value of the fatigue load is small, the deformation of the specimens is more pronounced than that under static load. Therefore, the deflection law of CFRP plate strengthened specimens under fatigue load was discussed. The strain distribution of the CFRP plate and the strain-load relationship of the CFRP plate in the mid-span position were given. The relationship between the crack occurrence position of the specimens and the strain distribution of the test specimens were investigated. In addition, it can also be used to judge the bonding performance of the CFRP-concrete interface, which can be used as an important indicator for evaluating fatigue failure. In this paper, combined with the characteristics of the fatigue crack growth rate, the fatigue life prediction analytical model for CFRP plate reinforced RC bridge roof was put forward. This model considering interface stress and fatigue damage accumulation of CFRP plate-reinforced bridge roof specimens according to the fatigue characteristics of bridge load. The model proposed in this paper could be applied to predict the fatigue life of the CFRP plate-reinforced RC bridge roofs.

\section{Bridge roof reinforcement and test scheme}

\subsection{Reinforcement scheme}

In the influence of different loads and the effect of concrete shrinkage and creep, lateral cracks or longitudinal cracks are prone to appeared on the roof of the box girder. Due to the excellent material properties of CFRP plate, a structural reinforcement scheme for strengthening the roof of bridge box girder with CFRP plate is proposed. The asphalt layer on the box girder was first removed before the CFRP plated was applied, and the insulation layer was set and the asphalt was re-paved. The reinforcement scheme of the box girder roof is shown as Figure 1.

According to different bridge load arrangement forms, the distribution of bridge moments under the most unfavorable conditions is calculated by structural force analysis, as shown in Figure 1. As can be seen from Figure 1, there is a maximum negative flexural moment at the root of the cantilever on the left side of the box girder. Therefore, in order to improve the operability of the test, the left half structure was selected and the equivalent simplification was performed through structural analysis. 


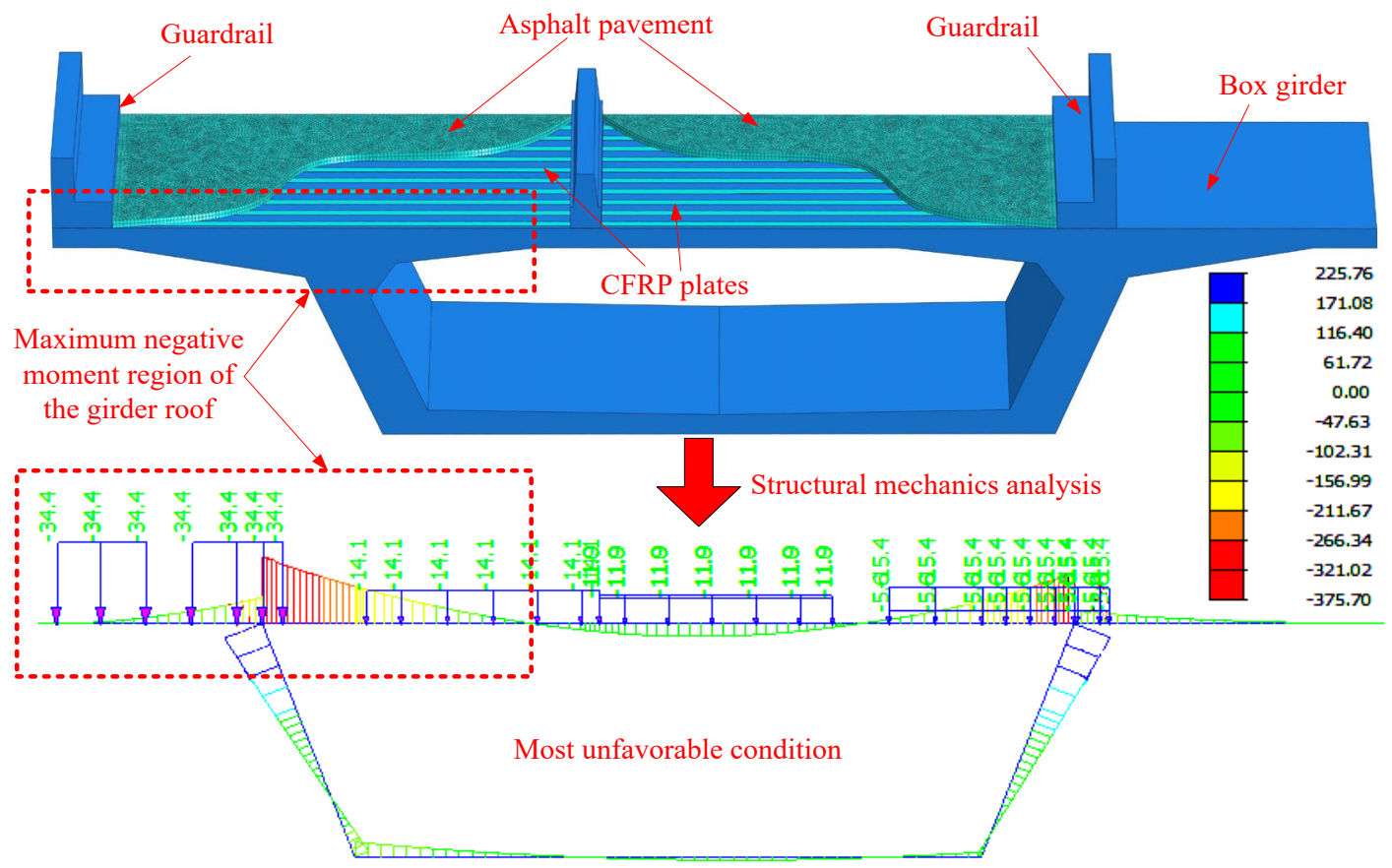

Figure 1: Reinforcement scheme and structural analysis of the box girder.

In order to reduce the possibility of mechanical properties changes in the CFRP-concrete interface layer due to the high temperature effect of asphalt paving, the arrangement of the heat insulation layer is proposed. The heat insulation layer was applied between the asphalt pavement layer and the CFRP plate reinforced box girder roof. Two different insulation layer schemes are proposed for comparison, different insulation layer schemes are shown as Figure 2. In the scheme A, the insulation layer is made of polyurethane, as shown in Figure 2(a). A polymer mortar leveling layer and a waterproof layer are set above the heat insulation layer. In the scheme $B$, the epoxy resin mortar is used as the heat insulation layer, and the arrangement of layers are shown in Figure 2(b).
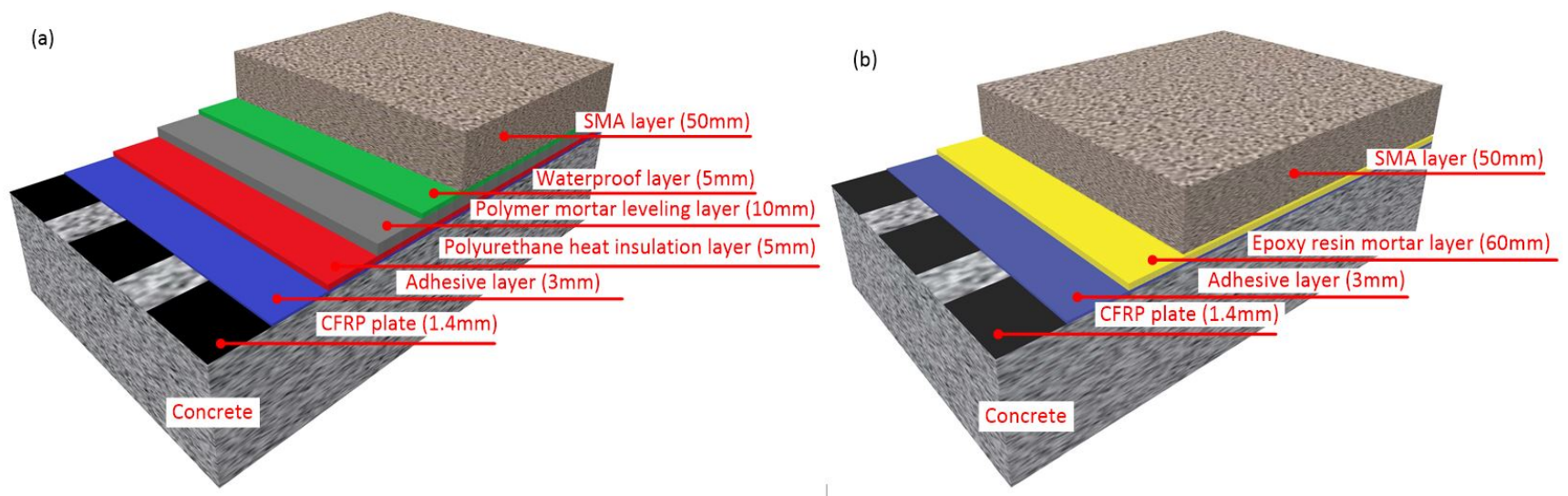

Figure 2 Two different insulation layer schemes: (a) pavement scheme A; and (b) pavement scheme B.

\subsection{Experimental procedure}

In order to study the fatigue characteristics and fatigue life of CFRP plates in the reinforcement of bridges with different deck paving scheme, the fatigue test was carried out on the CFRP plate reinforced concrete specimens. The fatigue performance and debonding failure mode of specimens with different pavement schemes were compared in detail. 
Through the mechanical analysis of the box girder, the test specimen is designed according to the equivalent principle of action effect. The details of specimen for fatigue test is shown as Figure 3 . The concrete specimens for fatigue test are reinforced by three pieces of CFRP plates, and the spacing between each CFRP plates is $150 \mathrm{~mm}$. The steel skeleton consists of two layers of longitudinal reinforcement on each side, and the steel ratio is $0.87 \%$. The $\Phi 12 \mathrm{~mm}$ stirrups with a spacing of $100 \mathrm{~mm}$ are used as shear reinforcement. The thickness of the concrete protective layer is $34 \mathrm{~mm}$. The length, width and thickness of the CFRP plate are $3400 \mathrm{~mm}, 100 \mathrm{~mm}$ and $1.4 \mathrm{~mm}$. respectively.

The strain distribution of the CFRP plate are measured during the fatigue test. The heat insulation layer and the asphalt pavement above the location of the measuring points were removed before the test, as shown in Figure 3 . The stain gauges are attached on the CFRP plates, and the arrangement of the strain gauges is closely arranged with free ends, sparsely arranged across the middle.

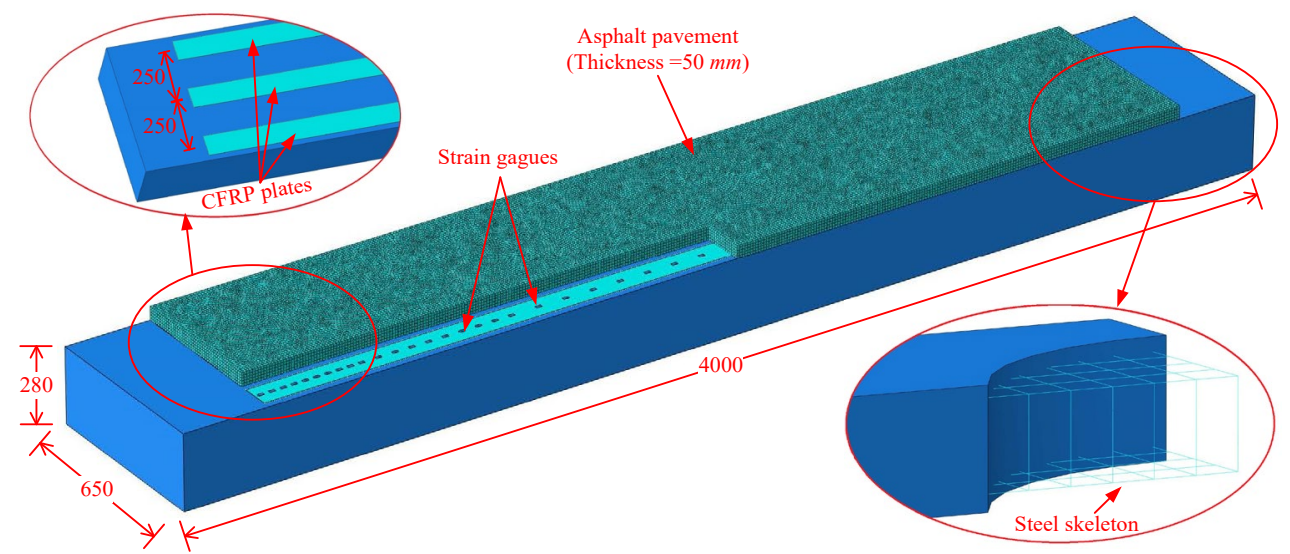

Figure 3: Diagram of CFRP plate-reinforced specimens for fatigue test (unit: $\mathrm{mm}$ ).

The CFRP-reinforced concrete specimens were tested and analyzed to study the fatigue characteristics of CFRP-reinforced bridge roofs with different deck pavement schemes. In addition, static specimens with different pavement scheme are also tested for comparison. The classification of specimens is shown in Table 1.

Table 1: Summary of test specimens.

\begin{tabular}{ccccc}
\hline Grouping of specimens & Test type & Specimen number & Deck pavement type & Reinforcement measures \\
\hline Contrast Specimen & Static test & FDBL-1 & None & None \\
& Static test & F-1 & Scheme A & CFRP plates reinforced \\
& & F-2 & Scheme B & Scheme A \\
Fatigue Specimens & Fatigue test & P-1 & Scheme B \\
\hline
\end{tabular}

The performance parameters of the CFRP plate are measured, the tensile strength, the tensile modulus and the elongation at break are equal or greater than $2300 \mathrm{MPa}, 150 \mathrm{GPa}$ and $1.4 \%$, respectively. The measured tensile strength and compressive strength of adhesive are larger than $25 \mathrm{MPa}$ and $70 \mathrm{MPa}$, and the tensile modulus of elasticity and the flexural strength are equal or larger than $2500 \mathrm{MPa}$ and $30 \mathrm{MPa}$, respectively. The grade C45 concrete and HRB 400 steel bar are adopted in this test. The characteristics value of concrete compressive strength and tensile strength are 29.6 MPa and 2.51 MPa according to the design code. The elastic model of the steel bar is $2.0 \times 10^{5} \mathrm{MPa}$, and the characteristics value of steel tensile strength is $400 \mathrm{MPa}$. 
Fatigue tests were conducted with an electro-hydraulic servo fatigue testing machine. The loading device for the fatigue and static specimens is shown in Figure 4.

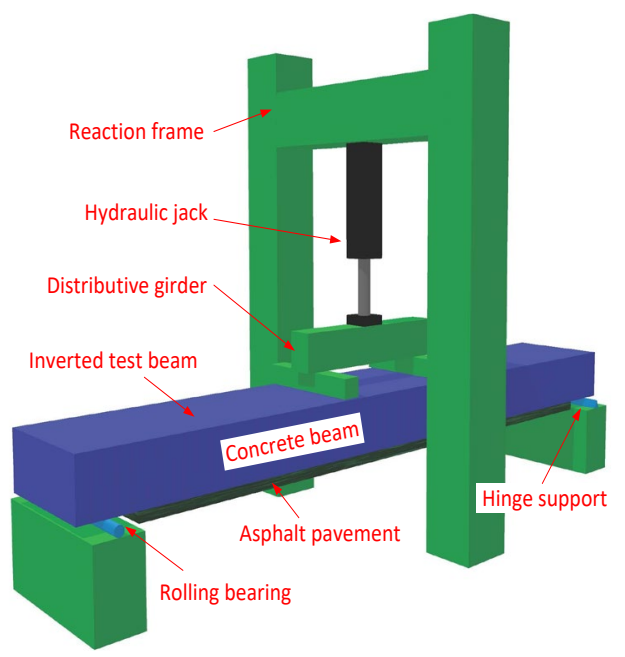

Figure 4: Test setup for the tests.

The ultimate bearing capacity of the static specimens are calculated firstly. The static test was also conducted on the static specimens to determine the practical ultimate bearing capacity of specimens, and the test load is divided into 10 levels according to the calculation value. A fatigue test was performed using $0.527 M$ as the fatigue load limit $M_{\text {max }}$ in which $M$ is the tested ultimate bearing capacity. The load form of the fatigue test is the sine wave with a loading frequency of $2 \mathrm{~Hz}$, and the total number of loadings is $2 \times 10^{6}$. The maximum value of stress amplitude is $251.5 \mathrm{MPa}$ and the minimum value of that is $104.8 \mathrm{MPa}$.

\section{Experimental results and analysis}

\subsection{Failure debonding form}

The failure mode of the specimen P-1 is shown in Figure 5. It can be seen from the figures that the pavement of the specimen P-1 is relatively poor bonded with the concrete beam. When the debonding failure of CFRP plates begin to occur, the asphalt layer separates from the heat insulation layer. When the specimen is broken, the polymer mortar between the adjacent CFRP plate also debonded due to the debonding failure of the CRPP plates.
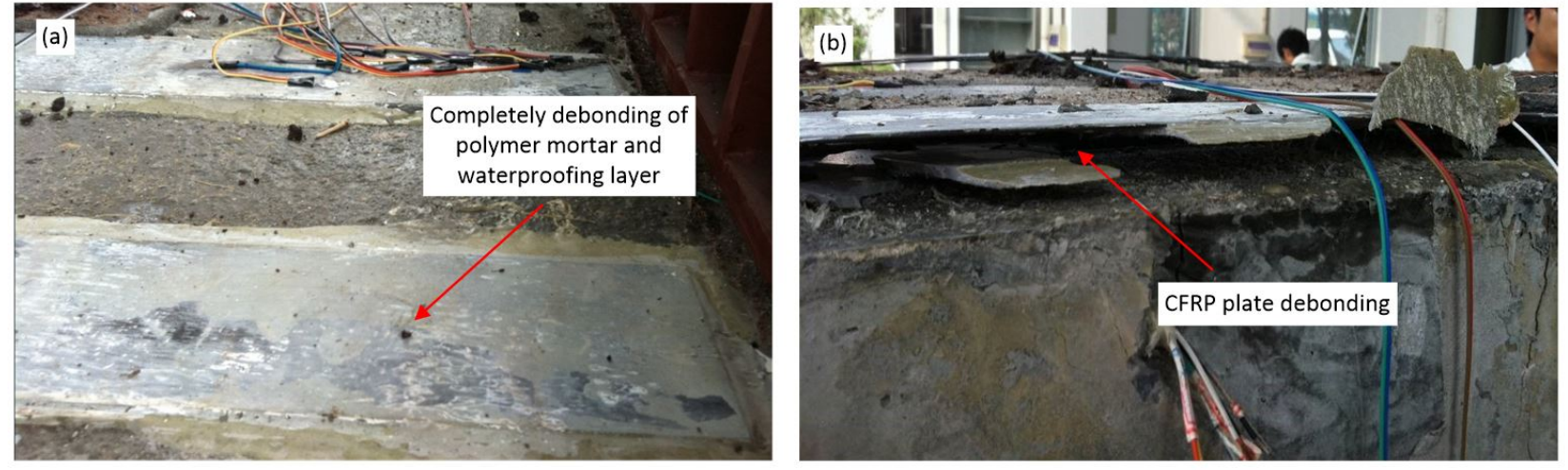

Figure 5: Failure form of the specimen P-1: (a) the surface of the CFRP plate after the pavement layer is completely debonded; and (b) the debonding of the polymer mortar layer caused by the debonding of the CFRP plate. 
For the specimen $\mathrm{P}-2$, the pavement layer paved according to the scheme $\mathrm{B}$ has better adhesion to the concrete beam and can maintain good integrity. The failure forms of the specimen after the fatigue test are shown in Figure 6. When the CFRP plate was debonded, only the epoxy mortar on the CFRP plate slipped together with the CFRP plate. When the specimen is fatigue-damaged, the adhesion of the asphalt layer to the epoxy mortar remains good.
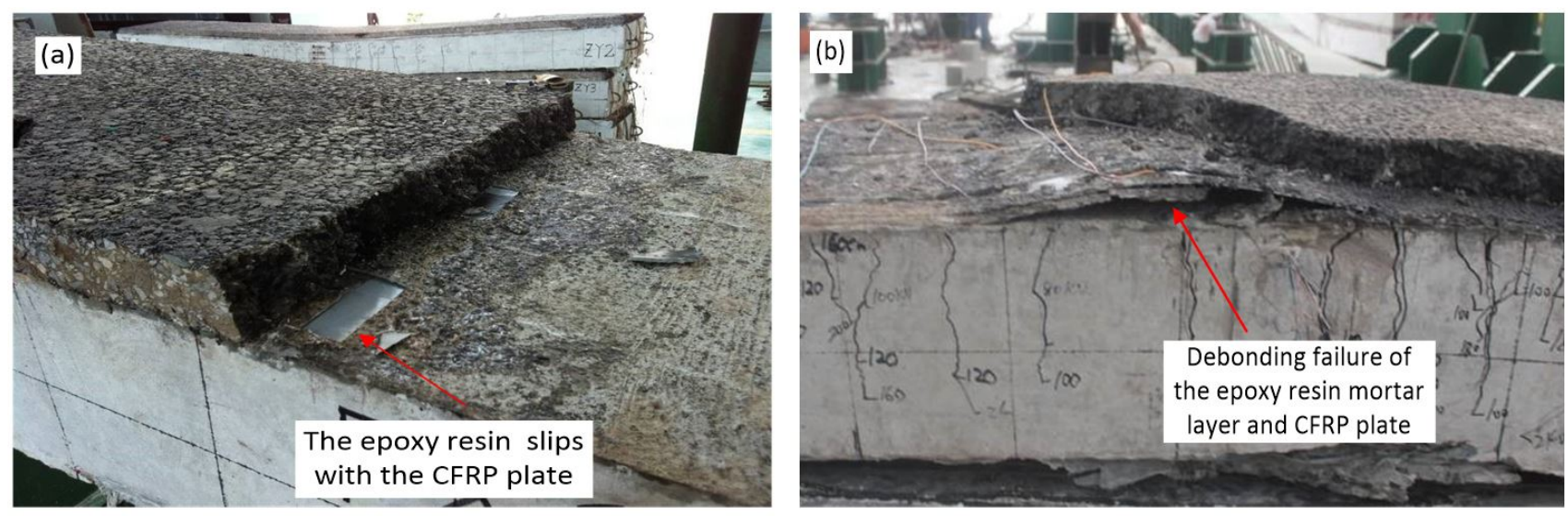

Figure 6: Failure debonding form of the specimen P-2: (a) debonding of the CFRP plate; and (b) debonding failure of the insulation layer and CFRP plate.

\subsection{Crack propagation}

Compared with specimens subjected to static load, the crack development of fatigue specimens under cyclic loading is relatively complicated. The maximum crack width exhibits regular expansion and closure with the change of load amplitude. As the number of cyclic loadings increases, the specimen may crack under the condition of lower ultimate load, and even the final debonding failure may occur.

After applying a certain number of fatigue cycle loads, a static load was applied on the specimen from $0 \mathrm{kN}$ to the estimated ultimate loading value of $120 \mathrm{kN}$. Fatigue load and static load are alternately loaded until the total number of fatigue loads reaches 2 million times. The crack morphology was observed at certain times of fatigue loads with a crack observer, and the fatigue crack distribution of the specimens are shown in Figures 7 and Figures 8.

(a)

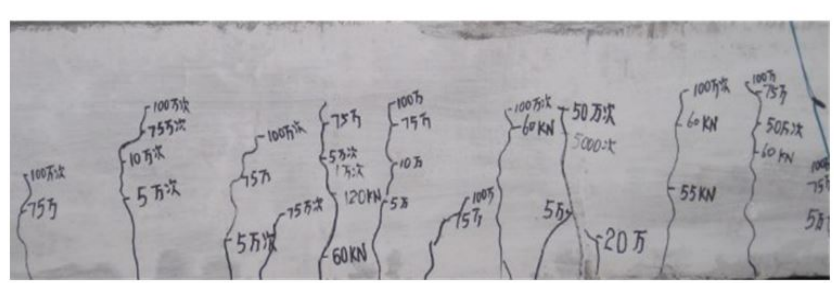

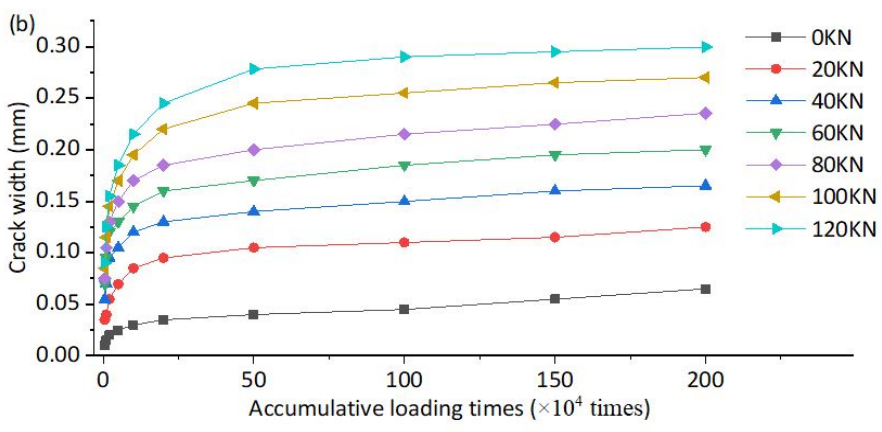

Figure 7: Crack of specimen P-1: (a) Crack development; (b) the crack - load frequency curve. 

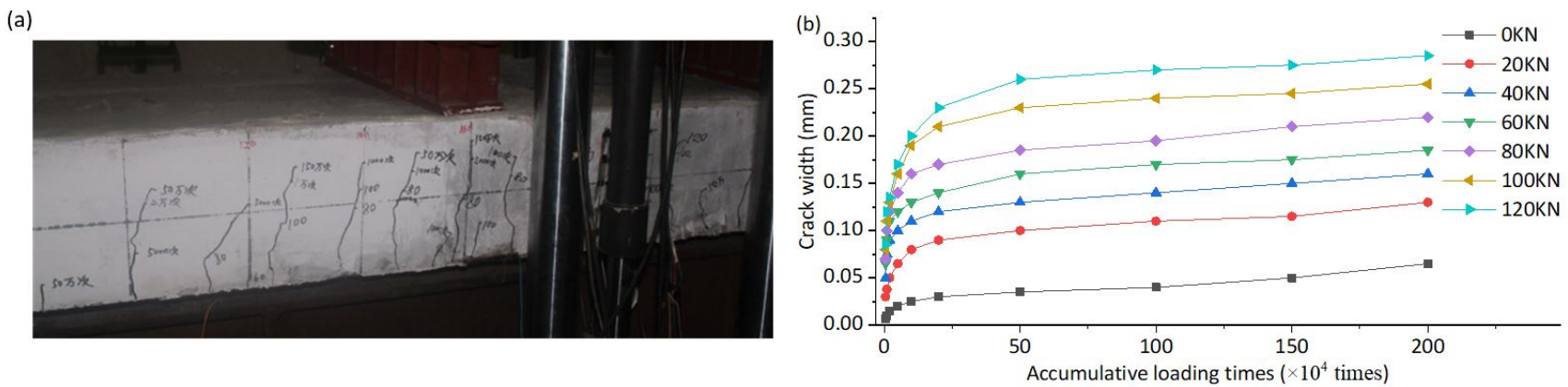

Figure 8 Crack of specimen P-2: (a) Crack development; (b) the crack - load frequency curve.

As can be seen from Figures 7 and 8 , as the fatigue load level and the number of fatigue cycles increase, the crack width and number of the specimens gradually increase. It can be concluded from the figures that the crack propagation of the specimen increases rapidly during the initial loading phase of the fatigue load, while the crack development is relatively slow during the following loading phase.

When the fatigue load level was $120 \mathrm{KN}$ and the loading number was 2 million times, the crack width of the specimen P-1 reached a maximum of $0.3 \mathrm{~mm}$, and that of the specimen P-2 reached a maximum value of $0.285 \mathrm{~mm}$. The maximum crack width of the fatigue specimens is relatively small compared to the average maximum crack width of the unreinforced specimen FDBL, which is $0.35 \mathrm{~mm}$. The test results show that the fatigue life of the specimen can be prolonged due to the reinforcement of the CFRP plates. And the CFRP plates can effectively prevent the development of cracks and improve the crack resistance of the concrete structure under the fatigue loading.

\subsection{Deflection development}

Structural deformation can be significantly increased under fatigue loading. Even when the value of the fatigue load is small, more significant deformation can be occurred than that under normal use conditions. Therefore, it is worthwhile to investigate the deflection of CFRP plate reinforced specimens under fatigue loading. And the deflection of the specimens effected by the high temperature action of asphalt paving under fatigue action is shown in Figure 9.
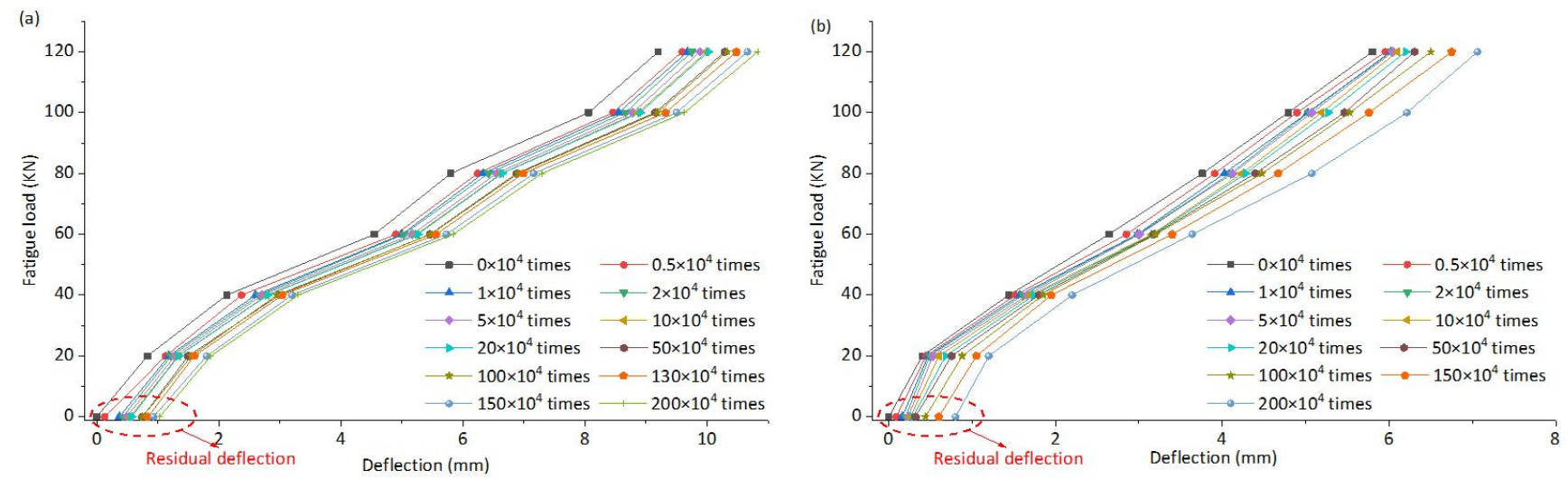

Figure 9: Deflection-load frequency relationship: (a) specimen P-1; and (b) specimen P-2.

It can be seen from the load-deflection curve, the deflection of the specimens generally increases with the increase of the fatigue load. And with the accumulation of the number of cyclic loadings, the residual deflection occurs. At the initial stage of loading, the deflection value increases rapidly with the increase of fatigue load, and the growth rate of deflection becomes slower in the later stage of loading. The maximum deflection of specimens reached a 
maximum of $10.83 \mathrm{~mm}$ and $7.06 \mathrm{~mm}$ after 2 million cycles of $120 \mathrm{kN}$ fatigue load, respectively. The maximum deflection is much smaller than that of the unstrengthen specimen. It indicated that the increase of the deflection can be better restricted with the reinforcement of the CFRP plates.

\subsection{CFRP plate strain distribution}

The stress and strain distribution of the specimen can be reflected by the crack length and position of the specimen. In addition, it can also be used to judge the bonding performance of the CFRP-concrete interface, which can be used as an important indicator for evaluating fatigue failure. The strain distribution of the CFRP plate and the strain-load relationship of the CFRP plate in the mid-span position are shown in the Figures 10 and 11.
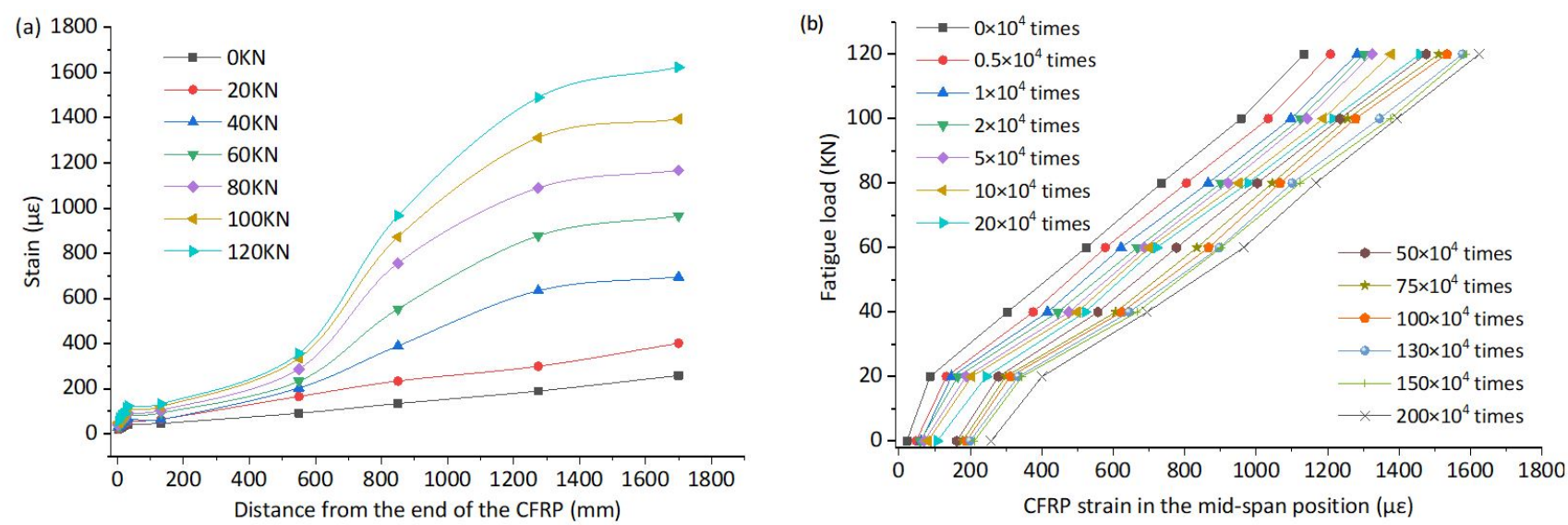

Figure10: Strain of the specimen P-1: (a) strain distribution of the CFRP plate; and (b) fatigue load-strain curve
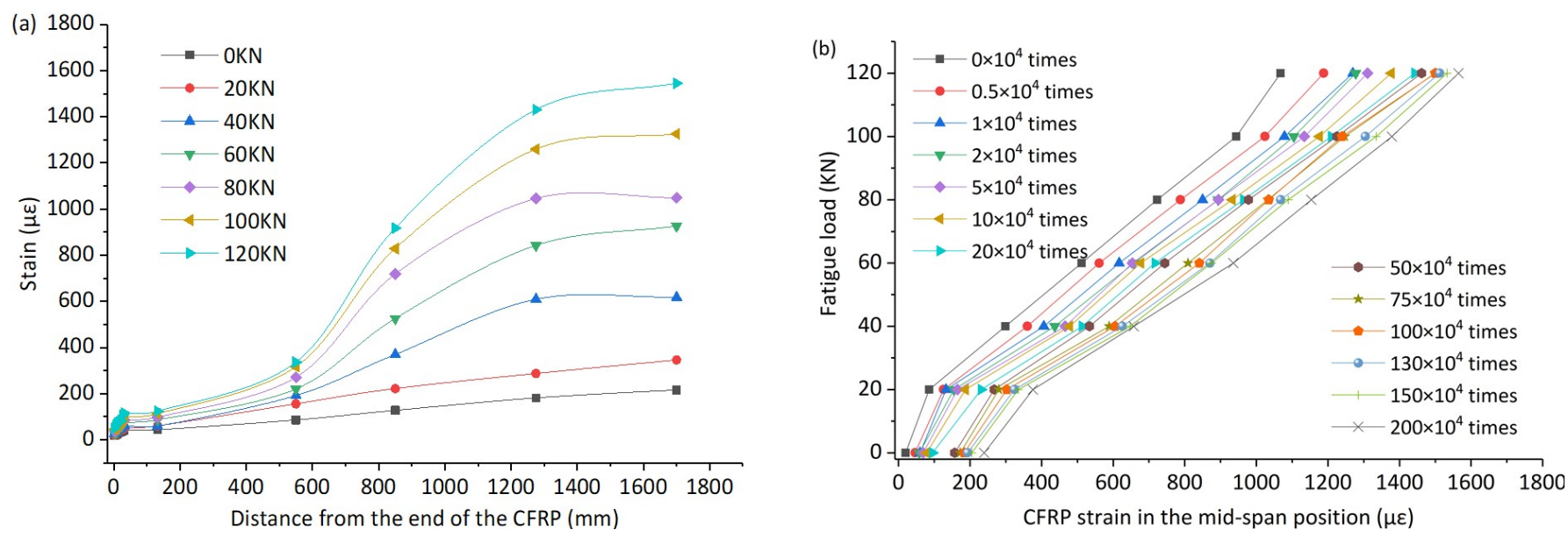

Figure 11: Strain of the specimen P-2: (a) strain distribution of the CFRP plate; and (b) fatigue load-strain curve

It can be seen from the Figures 10(a) and 11(a) that the strain at the in the mid-span of the CFRP plate is much larger than that at the end position. The strain value of the CFRP plate in the range of $600 \mathrm{~mm}$ at the end is small, and the strain value is less than $500 \mu \varepsilon$. As the load increases, the strain at the mid-span increases significantly, and the strain at the end position changes less.

As for the strain of the CFRP plate at the mid-span position, shown as Figures $10(b)$ and $11(b)$, the strain value in the span gradually increases as the fatigue load increases. Under fatigue loading, as the number of actions increases, residual strain occurs in the mid-strain of the CFRP plate. At this time, cumulative damage occurs, that is, fatigue 
damage occurs at the CFRP plate-concrete interface. Under 2 million times fatigue load with $120 \mathrm{KN}$ loading level, the maximum strain value of the CFRP plate in the mid-span of the specimen P-1 is $1624 \mu \varepsilon$, and that of the specimen P-2 is $1599 \mu \varepsilon$.

\section{Theoretical models for fatigue life prediction}

Based on the research on the crack propagation forms and failure modes of the CFRP plate reinforced concrete fatigue specimen, the fatigue life prediction model of CFRP plate in CFRP plate reinforced specimen can be obtained according to the analysis of the test results and the fracture mechanics analysis method.

\subsection{Stress intensity factor of interface crack}

The four-point flexural analysis model used for the CFRP plate reinforced RC specimen is shown in Figure 12. Due to the small thickness of the CFRP plate, the effect of the flexural moments and shear forces can be ignored. When a crack occurs at the interface between the CFRP plate and the concrete, the beam segment including the interface crack is selected, and the force analysis of the segment is performed as shown in Figure 13.

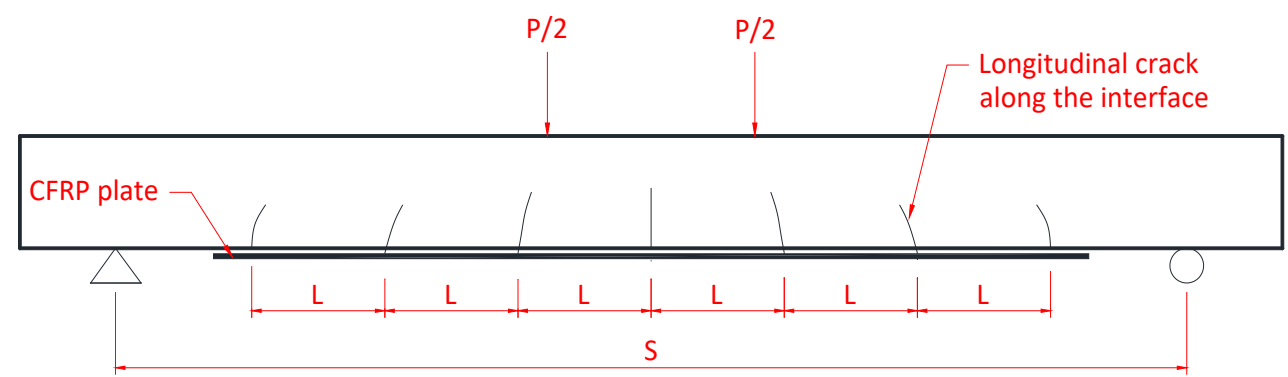

Figure 12: Analysis model for the CFRP plate reinforced RC specimen.

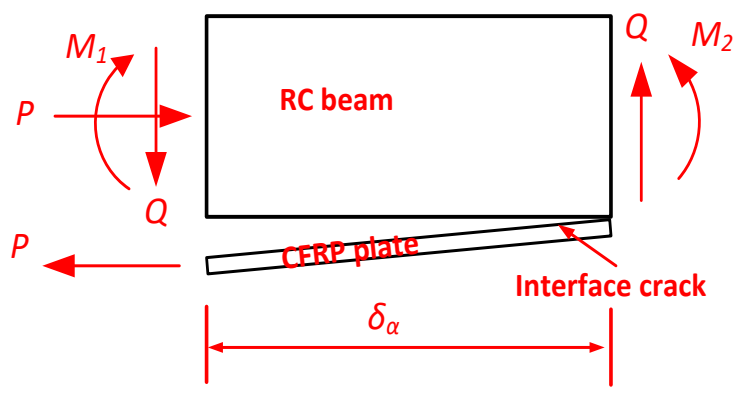

Figure 13: Interfacial stress analysis of the cracking segment.

The CFRP plates reinforced concrete beam in this study can be considered as a linear elastic member with cracks. Therefore, it can be studied based on the relevant principles of linear elastic fracture mechanics. Generally, the mechanical properties of cracking member can be analyzed from two aspects: energy release rate $G$ and stress intensity factor $\mathrm{K}$.

During the crack propagation process, for the surface where new cracks are generated, the energy of $d U$ provided by the outside world is required when generating a $d A$-sized fracture area. When the work performed by the external load on the cracking member is $d U_{e}$, a part of the energy remaining becomes elastic strain energy $d U_{s}$ and will be stored in the cracking member. Therefore, for the fracture area of $d A$, the rate of elastic strain release in the entire force system can be expressed by the following formula. 
$G=\frac{d U}{d A}=\frac{\partial\left(U_{e}-U_{s}\right)}{\partial A}$

For the test beam with width of $\mathrm{b}$ in this study, when the interface crack width is extended to $\delta_{\alpha}$, strain energy will be generated. The strain energy release rate of CFRP plate-concrete interface can be calculated by Equation 2.

$$
G=\frac{1}{\mathrm{~b}} \frac{\partial}{\partial a}\left(U_{e}-U_{S}\right)
$$

Where $U_{e}$ is the work done by external force; $U_{s}$ is the strain energy of the specimen; $b$ is the width of the specimen.

The CFRP plate reinforced concrete beam section is analyzed as an integral unit. Since the CFRP slab does not withstand shear forces, the shear stress will not cause changes in strain energy. According to the strain change of RC specimen and CFRP plate before and after crack propagation, the differential relationship between the interface crack length and the strain energy of the specimen can be obtained as follows:

$$
\frac{d U_{s}}{d a}=\frac{1}{2} P \varepsilon_{f}+\frac{1}{2} P \varepsilon_{r c}+\frac{1}{2}\left(\frac{M_{1}^{2}}{B_{r c}}-\frac{M_{2}^{2}}{B_{r c 0}}\right)
$$

$P=E_{f} b t_{f} \varepsilon_{f}$

$$
M_{2}-M_{1}=\frac{P h}{2}
$$

Where $E_{f}, \varepsilon_{f}, t$, and $L$ are the elastic modulus, the strain, the thickness and the length of the CFRP plate, respectively. $\varepsilon_{r c}$ and $h$ are the equivalent strain and the height of the RC specimen. $B_{r c}$ and $B_{r c o}$ are the flexural stiffness of the specimen and the sectional flexural stiffness of the CFRP reinforced beam.

Within the linear elastic range, $U_{e}$ is considered to be equal to $2 U_{s}$. The release rate of the strain energy can be obtained by substituting Equation 3 into Equation 2, and the formula is shown as follows.

$$
G=\frac{E_{f} t_{f} \varepsilon_{f}^{2}}{2}+\frac{\left(E_{f} t_{f} \varepsilon_{f}\right)^{2}}{2 E_{r c}^{\prime} h}+\frac{1}{2 b}\left(\frac{M_{1}^{2}}{B_{r c}}-\frac{M_{2}^{2}}{B_{r c 0}}\right)
$$

Where $E_{c}$ is the elastic modulus of concrete, and $E_{c}^{\prime}$ is the equivalent elastic modulus of the concrete beam.

In this paper, the bonding length of the CFRP plate is larger than $3 / 4 S$, where $S$ is the distance between the two bearings. Additionally, the debonding failure of the CFRP plate of the specimens first occurred in the mid-span position and developed to the end of the CFRP plate. The object analyzed in this paper is the crack at the interface between CFRP plate and concrete, which belongs to the crack type ${ }_{I I}$. The calculation formula of its stress intensity factor is as follows.

$$
K_{I I}=\sqrt{E G}=\sqrt{E_{c} \frac{E_{f} t_{f} \varepsilon_{f}^{2}}{2}}
$$


According to formula (7), it can be seen that the magnitude of the stress intensity factor is mainly affected by the concrete elastic modulus, CFRP plate elastic modulus, CFRP plate thickness, and CFRP plate strain. Reasonably limiting the strain value of CFRP plates in CFRP plate reinforcement engineering applications can effectively control the value of the interface stress intensity factor.

\subsection{Fatigue life prediction model}

As the number of fatigue loads increases and the crack propagates, the stress value at the crack tip decreases, and the crack enters a stable expansion and retention phase. During this phase, it can be observed from the specimens that the interface crack is gradually formed at the root of the fatigue main crack, and the interface crack gradually expands with the increase of the number of fatigue loading.

The crack propagation of concrete is related to the frequency of loading. When the loading frequency is low, the number of cracks in concrete specimens increases slowly with the increase of the number of fatigue loads. Under fatigue loading, the expansion rate of CFRP plate-concrete interface cracks can be expressed as Equation 8:

$$
d \alpha / d N=C(\Delta K)^{m}
$$

Where $\Delta K=K_{I I}-\left(K_{I I}\right)_{\min }$, and $\left(K_{I I}\right)_{\min }$ is the minimum value of stress intensity factor. $C$ and $m$ are the constant which can be obtained by fitting the test results. The stress intensity factor of the interfacial crack is proportional to the CFRP plate's stress, and the corresponding stress intensity factor value can be obtained based on the strain data of the CFRP plate measured in the fatigue test.

Considering that the CFRP plate strain value change is relatively small during the stable crack propagation phase, the CFRP plate strain value can be taken as the average value in the following discussion. If the effect of fatigue loading on the elastic modulus of concrete and CFRP plate is ignored, then the fatigue life calculation formula of the CFRP plate-concrete interface crack can be obtained by integrating the Equation 8 with substituting the Equation 7, and the formula is as follows.

$$
N=\frac{L}{2 C}\left(\left(\frac{E_{c} E_{f} t_{f} \varepsilon_{f}^{2}}{2}\right)-\left(\frac{E_{c} E_{f} t_{f}\left(\varepsilon_{f}^{0}\right)^{2}}{2}\right)^{1 / 2}\right)^{-m}
$$

Where $\varepsilon_{f}^{0}$ is the strain value corresponding to $\left(K_{I I}\right)_{\min }$.

It can be seen from Equation 9 that the strain of the CFRP plate is a key factor in determining the fatigue life of the interface crack. It can be also concluded from Equation 7 that the stress intensity factor is proportional to the stain of the CFRP plate. The proportional coefficient can be obtained by fitting, and the result is shown as Figure 14 . 


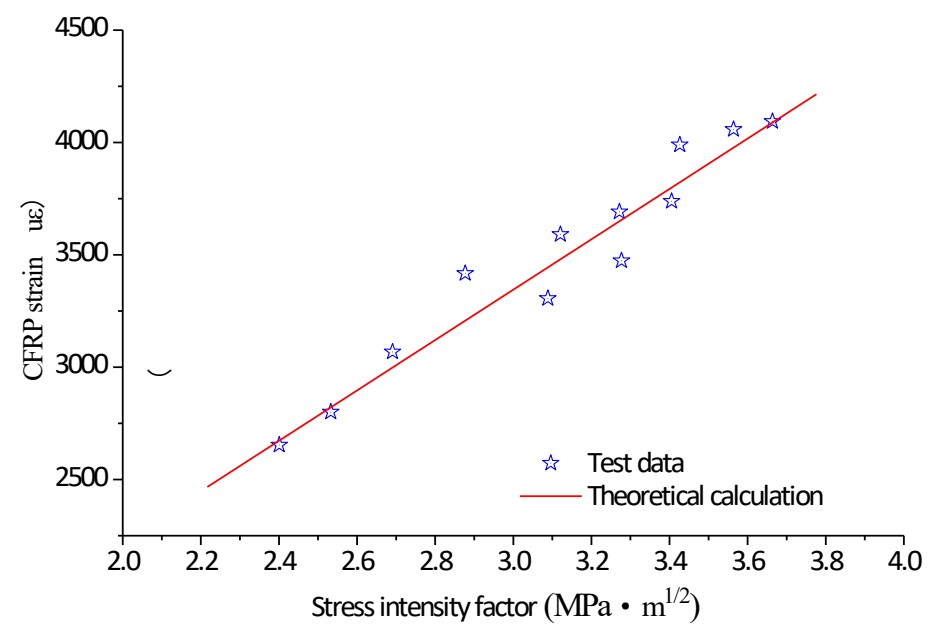

Figure 14: Relationship between the stress intensity factor and the CFRP strain.

The fatigue test results are shown in Table 2. When the CFRP plate strain is less than its critical value, the interface of the CFRP plate and concrete will not suffer from fatigue damage.

Table 2: Results of the fatigue tests

\begin{tabular}{cccc}
\hline Specimen number & Load level / kN & CFRP plate average strain value / $\mu \varepsilon$ & Fatigue life / Cycle \\
\hline P-1 & 120 & 1624 & $>2 \times 10^{6}$ \\
& 125 & 1832 & $756244 \sim 1587694$ \\
& 130 & 2353 & $731589 \sim 1263951$ \\
& 135 & 2987 & $603598 \sim 965237$ \\
& 140 & 3763 & $523687 \sim 658413$ \\
P-2 & 145 & 4698 & $356244 \sim 487694$ \\
& 120 & 1599 & $>2 \times 10^{6}$ \\
& 125 & 1769 & $753587 \sim 1575624$ \\
& 130 & 2037 & $729546 \sim 1248521$ \\
& 135 & 2865 & $600585 \sim 960258$ \\
& 140 & 3564 & $520325 \sim 651256$ \\
& 145 & 4486 & $351369 \sim 478564$ \\
\hline
\end{tabular}

According to the test result of the specimens, the constant in the Equation 9 can be obtained as follows: $C$ equals $1.58 \times 10^{-14}$ and $m$ equals 1.36 . And the interface crack fatigue extended life formula can be obtained as follows by substituting the above parameters into Equation 9.

$N=4.47 \times 10^{13}\left(8.85 \times 10^{8} \varepsilon_{f}-2.53 \times 10^{6}\right)^{-1.39}$

It can be seen from the Equation 10 that the fatigue life of the CFRP plate-concrete interface crack can be simply predicted based on the strain value of the CFRP plate tested in the fatigue test. 
The relationship between the fatigue life and the CFRP stain is shown in Figure 15. The proposed calculation model for predicting the fatigue life is verified by comparing the test results of the specimen P- 2 with the theoretical calculation value, and the comparison result is shown as Figure 15.

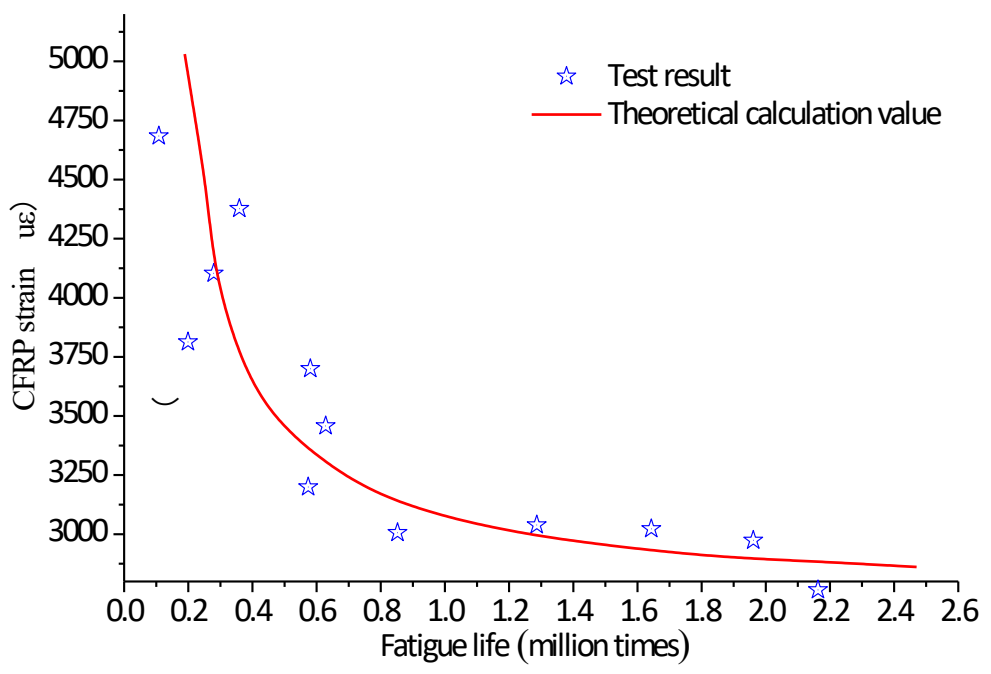

Figure 15: Comparison of the calculating values and the experimental data for fatigue life

It can be seen from Figure 15 that when the strain of the CFRP plate is below $3000 \mu \varepsilon$, the predicted fatigue life increases rapidly with the decrease of strain value. While the strain exceeds this critical value, the variation of the fatigue life and strain turns to the opposite. Moreover, the comparison results presented in Figure 15 also show that the theoretical prediction value obtained by Equation 10 is close to the experimental result. It indicates that the fatigue life prediction model recommended in this paper can effectively predict the fatigue life of the interface cracks in the CFRP plate reinforced RC specimens.

\section{Conclusions}

This paper investigated the fatigue properties and life prediction of the CFRP plate-reinforced bridge with different deck pavement schemes. Two deck pavement schemes of CFRP-reinforced specimens were designed and tested. The fatigue crack propagation, the deflection development regulation and the CFRP strain under fatigue load were analyzed. Combined with the characteristics of the crack growth rate, the fatigue life prediction analytical model for CFRP plate reinforced bridge roof was obtained. The following conclusions can be drawn:

(1) The specimens reinforced with CFRP plates of two different type bridge deck pavements can meet the requirement of the fatigue test load of two million times.

(2) The maximum crack width in the test beam reinforced with the CFRP plate is less than that of the contrast beam. The cracking resistance ability can be improved in the specimen reinforced with the CFRP plate.

(3) The ultimate bearing capacity and fatigue life of the test beam reinforced with the CFRP plate can be improved to a certain degree.

(4) The cracking height of the reinforced specimen increases as the increase of the fatigue load value, and it can be maintained at a constant value in the final stage of fatigue failure.

(5) The fatigue life calculated by the recommended prediction model agrees well with the experimental results. The model proposed in this paper can be applied to predict the fatigue life of the CFRP plate-reinforced bridge roofs. 


\section{Acknowledgements}

This work was financially supported by the National Natural Science Foundation of China (Grant No. 51508368), the Brand Professional Funding Project of Jiangsu Province (Grant No. PPZY2015B143), the Postgraduate Research \& Practice Innovation Program of Jiangsu Province (Grant No. SJCX18_0879), and the Key Project of Innovation and Entrepreneurship of College students in Jiangsu Province (Grant No. 201810332019Z).

Author's Contributions: Conceptualization, $X$ Yuan and W Zheng; Methodology, $X$ Yuan; W Zheng and CY Zhu; Investigation, $X$ Yuan; $C Y$ Zhu and BJ Tang; Writing - original draft, $X$ Yuan and $W$ Zheng; Writing - review \& editing, $X$ Yuan; $W$ Zheng and YY Zhang; Funding acquisition, $X$ Yuan and CY Zhu; Resources, $X$ Yuan and CY Zhu; Supervision, $X$ Yuan and BJ Tang.

Editor: Pablo Andrés Muñoz Rojas.

\section{References}

Barile, C., Casavola, C., Vimalathithan, P.K., Pugliese, M., Maiorano, V. (2019). Thermome chanicaland Morphological Studies of CFRP Tested in Different Environmental Conditions. Materials 12(1), 63:1-16.

Guo, X.Y., Wang, Y.L., Huang, P.Y., Zheng, X.H., and Yang, Y. (2019). Fatigue Life Prediction of Reinforced Concrete Beams Strengthened with CFRP:Study Based on an Accumulative Damage Mode. Polymers 11(1),130:1-18.

Guo, X.Y., Yu, B., Huang, P.Y., Zheng, X.H., and Zhao, C. (2018). J-integral approach for main crack propagation of RC beams strengthened with prestressed CFRP under cyclic bending load. Engineering Fracture Mechanics 200:465-478.

Hosseini, A., Ghafoori, E., Al-Mahaidi, R., Zhao, X.L., and Motavalli, M. (2019). Strengthening of a 19th-century roadway metallic bridge using nonprestressed bonded and prestressed unbonded CFRP plates. Construction and Building Materials. 209:240-259.

Ju, M., Oh, H., Sim, J. (2017). Indirect fatigue evaluation of CFRP-reinforced bridge deck slabs under variable amplitude cyclic loading. ksce journal of civil engineering. 21(5):1783-1792.

Kalavagunta, S., Naganathan, S., and Mustapha, K. N. (2014). Axially loaded steel columns strengthened with CFRP. Jordan Journal of Civil Engineering 8(1): 58-69.

Li, D.Y., Huang, P.Y., Qin, G., Zheng, X.H., and Guo, X.Y. (2017). Fatigue Crack Propagation Behavior of RC Beams Strengthened with CFRP under High Temperature and High Humidity Environment. International Journal of Polymer Science. Article ID 1247949:1-11.

Li, L.Z., Chen, T., Zhang, N.X. (2019). Test on fatigue repair of central inclined cracked steel plates using different adhesives and CFRP, prestressed and non-prestressed. Composite structures. 216:350-359.

Liang, H.J., Li, S., Lu, Y.Y., Yang, T. (2018). Reliability Analysis of Bond Behaviour of CFRP-Concrete Interface under Wet-Dry Cycles. Materials 11(5), 741:1-14.

Lin, J.X., Huang, P.Y., Guo, X.Y., Zheng, X.H., and Zhao, C. (2019). Fatigue performance of RC beams strengthened with CFRP under coupling action of temperatures and vehicle random loads. Fatigue Fract Eng Mater Struct 42:31-44. 
Lu, Y.Y., Hu, J.Y., Li, S., Tang, W.S. (2018). Active and passive protection of steel reinforcement in concrete column using carbon fiber reinforced polymer against corrosion. Electrochim. Acta 278, 124-136.

Mashrei, M.A., Makki, J.S., and Sultan, A.A. (2019). Flexural strengthening of reinforced concrete beams using carbon fiber reinforced polymer (CFRP) sheets with grooves. Latin American Journal of Solids and Structures. 16(4): e176.

Peng, H., Zhang, J., Cai, C.S., Liu, Y. (2014). An experimental study on reinforced concrete beams strengthened with prestressed near surface mounted CFRP strips. Engeering. Structure 79:222-233.

Saleem, M.U., Qureshi, H.J., Qureshi, M.N., Khan, K., and Khurshid, H. (2019). Cracking behavior of RC beams strengthened with different amounts and layouts of CFRP. Applied Sciences-Basel 9: 10-17.

Shukri, A.A., Shamsudin, M.F., Ibrahim, Z., Alengaram, U.J., and Hashim, H. (2018). Simulating intermediate crack debonding on RC beams strengthened with hybrid methods. Latin American Journal of Solids and Structures 15(9), e78.

Siddika, A., Mamun, Md. A.A., Alyousef, R., Amran, Y.H.M. (2019). Strengthening of reinforced concrete beams by using fiber-reinforced polymer composites: A review. Journal of Building Engineering 25,100798:1-12.

Song, L., and Hou, J. (2017). Fatigue Assessment Model of Corroded RC Beams Strengthened with Prestressed CFRP Sheets. International Journal of Concrete Structures and Materials.11:247-259.

Yang, Y., Jiang, Y., Jiang, H., Yin, X., and Huang, Y. (2019). Study on Tensile Properties of CFRP Plates under Elevated Temperature Exposure. Materials, 12(12), 1995:1-10.

Yuan, X., Zhu, C., Hu J., and Zhang, Y. (2019) Crack and mechanical behavior of CFRP plate-reinforced bridge roofs under high temperature with different anchoring measures. Latin American Journal of Solids and Structures. 16(6), e206

Zeng, J.J., Gao, W.Y., Liu, F. (2018). Interfacial behavior and debonding failures of full-scale CFRP-strengthened H-section steel beams. Composite Structures. 201:540-552.

Zhang, L., Cao, S.Y., Tao, X. (2019). Experimental Study on Interfacial Bond Behavior between CFRP Sheets and Steel Plates under Fatigue Loading. Materials 12(3), 377:1-14.

Zhuang, N., Dong, H.H., Chen, D., and Ma, Y.M. (2018) Experimental study of aged and seriously damaged RC beams strengthened using CFRP composites. Advances in Materials Science and Engineering, Article ID 6260724, 1-9. 